- laws. Texas's supply of pentobarbital expired in September, but the state obtained more from unregulated compounding pharmacies, which tailor-make drugs. Pentobarbital is not "especially" useful as a surgical anaesthetic, says Lubarsky, so its shortage has little impact on patient care.

On 15 October, after running out of pentobarbital, Florida executed William Happ using midazolam as the sedative. But midazolam, which is similar to diazepam (Valium), had never been used in an execution, and, according to media reports, Happ was still blinking and moving his head minutes after the injection.
Nobody knows whether midazolam is appropriate for lethal injections, says Lubarsky. "We've turned this into a circus of experimenting on prisoners," he says. "The state is playing doctor without any regard for efficacy. It changes protocols willy-nilly." The drug is not a good anaesthetic, he says, and it may not shield prisoners from the pain of the final injection.

Although midazolam has now entered the realm of capital punishment, it is unlikely that surgical supplies will be affected. Hospira is one of many companies that makes midazolam and has no plans to stop, says Dan Rosenberg, a company spokesman. Rosenberg would not say where Hospira makes midazolam, but he says that European regulations "aren't an issue".

Meanwhile, Missouri has suspended another execution, scheduled for 20 November, while it tries to find an alternative to propofol. Lubarsky notes that although a single, large dose of propofol could work as a method of execution, its use in US prisons would be problematic because it could be complex to administer and physicians are generally not willing to participate in the process (see Nature 441, 8-9; 2006). "Putting together a foolproof protocol that could be carried out by prison guards with high-school educations is another matter entirely," he says. .

\title{
Brazil fêtes open-access site
}

\section{South American SciELO project weighs up future after 15 years of free publishing.}

\section{BY RICHARD VAN NOORDEN}

$\mathrm{R}$ esearchers and publishers are gathering this week in São Paulo, Brazil, to celebrate a quietly subversive openaccess publishing project. The occasion: the 15th anniversary of SciELO (Scientific Electronic Library Online), a subsidized collection of mainly Latin American journals that now puts out more than 40,000 free-to-read articles each year - and which aims to put developing countries firmly on the scientific map.

Although little noticed by European and North American scientists, SciELO is "one of the more exciting projects not only from emergent countries, but also in the whole world", argues Jean-Claude Guédon, an open-access supporter who studies comparative literature at the University of Montreal in Canada.

In contrast to fee-charging open-access journals, journals on the SciELO platform charge authors little or nothing to publish because state and government funders provide infrastructure and software. That backing has helped to make Brazilian research the most open in the world - in 2011, 43\% of Brazilian science articles were free to read on publication, compared with, for example, $6 \%$ of US articles.

But on its 15th birthday, SciELO's future is in flux. Broader recognition of the venture might inspire similar 'public-good' networks in other emerging science regions. Or the project might dwindle in influence as commercial open-access publishers muscle in. "The direction that SciELO goes in will have a big effect on scholarly communications in Latin America," says Juan Pablo Alperin, a doctoral student at Stanford University in California who develops software at the Public Knowledge Project, a research initiative

\section{FREE AND EASY}

SciELO has expanded rapidly. For comparison, the global number of immediately available open-access articles published in 2011 was 340,000.

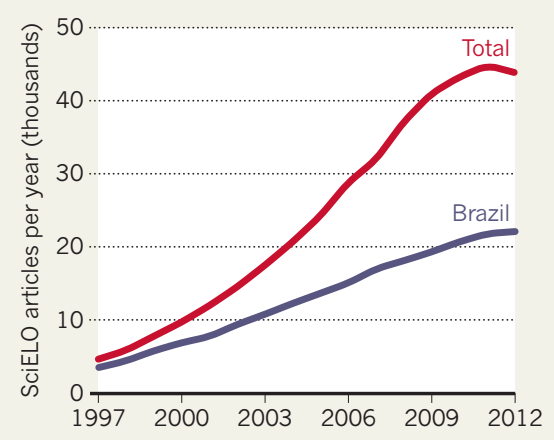

looking at open-access scholarly publishing.

The roots of SciELO go back to 1993, when Rogério Meneghini, now SciELO’s scientific director but then at the São Paulo Research Foundation (FAPESP), saw that "a great deal of [Brazil's] scientific conversation was not noticed in global science". In an effort to raise the visibility of Brazilian research, FAPESP started funding SciELO as a one-year pilot project in 1997, with journals that met basic editorial standards being placed in the collection. Ten other countries, including Mexico, Spain and South Africa, subsequently joined. And it has inspired other free Ibero-American publishing platforms, such as the 11-year-old Redalyc.org.

Much of the project is funded by a US\$3-million annual grant from FAPESP and from Brazil's National Council for Scientific and Technological Development, says SciELO director Abel Packer. Separately, some journals offer extra services, such as English translation. And each country supports its own journal operations (South Africa, for example, has chipped in with $\$ 450,000$; Chile, with $\$ 345,000$ ).

SciELO's admirers say that the system builds publishing expertise and helps researchers to publish open science on regional subjects such as health issues and farming techniques - that might be rejected by international journals. However, citations are low and journal quality variable. Many Brazilian researchers choose instead to publish in international journals, notes Margareth Capurro, a biologist at the University of São Paulo. This is partly because funding agencies prefer higher-impact publications, she adds.

"If 'influence' were measured by other ways, such as usage, we may see a different picture," says Leslie Chan, who studies open access at the University of Toronto in Canada. SciELO Brazil gets 1.5 million downloads per day, and this year, a SciELO citation database will be added to the Thomson Reuters Web of Knowledge, further raising visibility.

Packer and Meneghini hope to persuade other emergent science nations to join: India has been approached. They say that, for the Brazilian journals, the greatest challenges are to raise journal quality and international recognition. This might involve professionalizing editorial boards and paying salaries. But that could mean higher costs, says Meneghini.

As SciELO grows (see 'Free and easy'), its biggest journals are in danger of being bought by profit-seeking publishers, warns Guédon. That would be a shame, Alperin says, adding that a free-to-publish system helps to sidestep problematic aspects of open-access publishing, such as when fee-charging journals accept as many papers as possible without providing adequate peer review. "I'd love to see more of the world copy the Latin American model," he says. - 